\title{
Design of Strawberry Fruit Packaging for Agribusiness Small and Medium Enterprises in Cinumpang Village
}

\author{
Krishnanda Raditya Mooduto
}

${ }^{I}$ Nusa Putra University, Sukabumi, Indonesia

*Corresponding author. E-mail: krishnanda.raditya@nusaputra.ac.id

\begin{abstract}
This project, which the Department of Visual Communication Design initiated at Nusa Putra University for SMEs in Cinumpang Village, Sukabumi Regency, West Java, involved lecturers and SMEs in Cinumpang Village Sukabumi Regency, West Java. The community seeks to maximize the agricultural potential of their tourism attractions to increase their productivity. According to data gathered from interviews with garden owners, the area will be transformed into an international tourism and agriculture destination. This is meant to be a source of income for inhabitants and an integrated system. Because the intended market for strawberries was primarily women, an appealing, distinctive, and more feminine design resulted from the Cinumpang Village SMEs' strawberry fruit package design. With the presence of this packaging, it is envisaged that it will be able to meet the demand for strawberry packing among Cinumpang Village's MSME agribusinesses.
\end{abstract}

Keywords: Packaging, Strawberries, MSMEs, Cinumpang Village.

\section{INTRODUCTION}

The pandemic hit MSMEs in the micro food and beverage industry, with the average impact reaching 27 percent. MSMEs have been affected by COVID-19 since early 2020, and according to data processed by P2E LIPI, the impact of the decline in tourism on business actors. In the meantime, the impact on small food and beverage firms was 1.77 percent, while the impact on medium operations was 0.07 percent and had climbed by more.

Covid 19 produced a pandemic around the beginning of 2020, negatively influencing the state, the larger population, and notably traders. The look and conduct of the economic order and its diverse consequences on the field and people's lives have changed from month to month. The BPS in 2021 reveals negative news that Indonesia's economic performance has declined from the first quarter of 2020 , as seen by the data on the first quarter of 2020 's growth rate of 2.97 percent. The second quarter of 2020 saw a dramatic fall, with a growth rate of negative 5.32 percent. The government must address this reduction in economic data right away because it will impact both near and long-term sustainability. The government's efforts to limit the spread of the COVID-19 outbreak in Indonesia include prohibiting crowding (social distancing) and different temporary closures in various sectors. As a result, the decision was made to implement LargeScale Social Restrictions (PSBB) to have a more significant impact on the population and allow for the formation of new clusters due to the COVID-19 outbreak [1].

Another effect on the MSME sector since the COVID-19 pandemic has been a drop in monthly income of traders due to the difficulty of access that is usually passed, and consumers survive in challenging economic conditions. It is not uncommon for them not to shop for some necessities due to wait and see conditions [2].

Agribusiness MSMEs, such as Cinumpang Strawberry Village in Sukabumi Indonesia, have also experienced this. This strawberry farm is situated on the slopes of Kadudampit District, West Java, at the foot of Mount Gede Pangrango Sukabumi. The company has been in operation for nearly eight years. Visitors to agro-tourism villages and strawberry orders have continuously increased every year before the outbreak. In addition to strawberries, this plantation has several focuses on 
cultivated crops, namely: strawberries, ciplukan, oranges, corn, coffee, and honey farming, and occupies a total area of approximately 30 hectares.

In addition to strawberries, this plantation has several focuses on cultivated crops, namely: strawberries, ciplukan, oranges, corn, coffee, and honey farming, and occupies a total area of approximately 30 hectares. Packaging is needed for MSMEs because, according to FAO, damage during shipping to trade locations in several developing countries has increased by around $20 \%$ to $52 \%$. In comparison, it is around $5 \%$ to $12 \%$ in developed countries, and this data continues to grow. This is probably due to the needs, location of the plantation, and how it is delivered, so handling and packaging need to be considered [3].

Global competition is getting stronger in this millennial era. The threat of imported food is also a problem if domestic manufacturing is not equipped to deal with it and the quality of the product and packaging that has been created. According to the Ministry of Cooperatives and Small and Medium Enterprises (MSMEs), the priority sector in the food industry is MSMEs, which have promising potential for traders and national economic development. Following Law No. 20 of 2008 concerning Micro, Small and Medium Enterprises which contains the following:

1) Micro Enterprises are productive businesses owned by individuals or individual business entities that meet the criteria for microbusinesses as regulated in this law.
2) Small business is a productive economic business that operates independently and is operated by individuals or business entities that are not subsidiaries or branches of a larger or medium-sized company that are owned, controlled, monitored, or become a direct or indirect part of the larger or medium-sized company that meets the law's minor business criteria.

3) Medium-sized firms are self-contained productive and creative economic enterprises operated by persons or business entities directly or indirectly affiliated with a more giant or medium-sized corporation that fulfills the law's definition of a small business.

\section{RESEARCH METHODS}

The method for generating this strawberry fruit packaging design is qualitative, with business owners and field actors employing a method approach (Research and Development / R\&D). The purpose of research using the Research and Development strategy is to study a product or service sales flow and test the method's performance. It is envisaged that the direction of the design goals would become more precise and more focused due to these stages.

The stages in the research were carried out using the following steps:

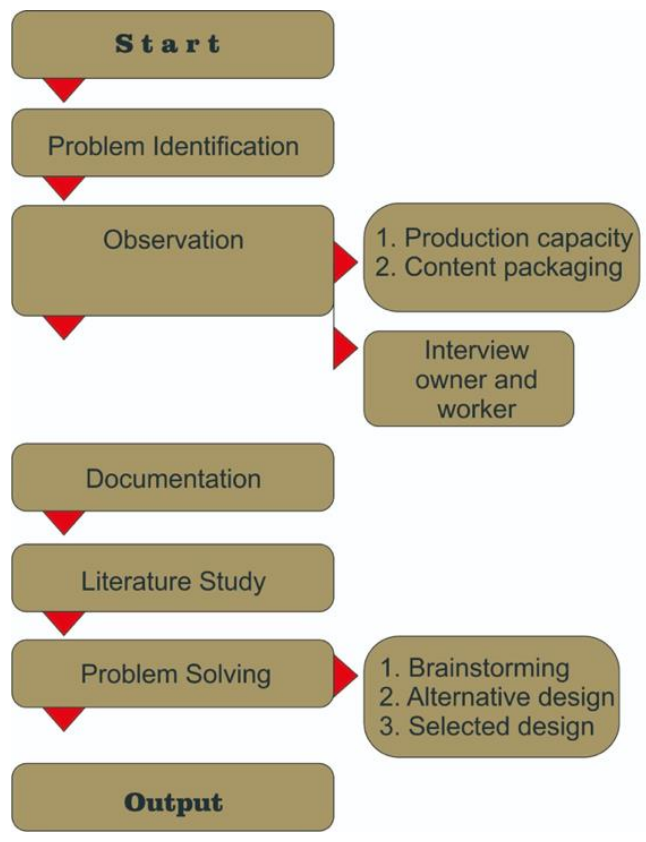

Figure 1. Stages of the Research and Development method 
The study took place in the Sukabumi district's Cinumpang agro-tourism and plantation region. Data from the field will be gathered, analyzed, and developed to meet the needs of the strawberry plantation business. Several procedures will be taken to collect details about this approach, including:

1) Observation. This is the stage in which researchers pay close attention to the product under development, the nature of the fruit, and the packaging procedure until the product is ready for sale. Characteristics, colors, fonts, and the materials used for fruit packaging are all managed.

2) Interview. Interviews with business owners and performers are needed to determine the potential and image that will be emphasized in various aspects of the packaging design that will be created.

3) Documentation. This activity will document actions, strawberries exposed to visual aspects and marketed, and an understanding of the strawberry's nature.

4) Review of the literature. This research is part of a sequence of designs that include looking for related sources to help with packaging research and design. To design the packaging, materials, font, colors, images, slogans, local culture, and some supporting information will be examined and developed.

This packaging design will utilize the Strengths, Weaknesses, Opportunities, and Threats (SWOT) methods, namely:

1) Strengths: The robustness of the condition of SMEs in Cinumpang Village is explored holistically at this point. Looking at the field, all SMEs have a strong awareness of the many plants grown in the area, including how to feed, care for, and collect fruit and control pests on plants.

2) Weaknesses: It is mentioned how the flaws of the SMEs' condition in Cinumpang Village are holistic. Due to the limited size of this SME area and its proximity to a protected forest region, output has not been able to expand rapidly. This affects the annual strength of the production. Aside from that, there are numerous competitors from different places, both inside Sukabumi and outside West Java, necessitating an appealing packaging strategy tailored to the target market and distinct.

3) Opportunities: At this stage, it is stated how the potential arising from the SMEs' current state in Cinumpang Village are considered holistically. The Cinumpang Village MSMEs can use the 4.0 sales potential in this millennial era. Can use social media, electronic media, and print media, among other things. Intercropping can also be used in terms of production.

4) Threats: At this point, it is addressed how the threat posed by Cinumpang Village's SMEs is holistic. Because this is an agribusiness area, there are bound to be dangers from both within and without. Employees with insufficient human resources and skills pose a threat from the inside. Planting and handling the fruit and selling and exposing it to social media, the internet, and other media require talents.

\section{RESULTS AND DISCUSSION}

\subsection{The impact of the pandemic on Strawberry MSMEs in Cinumpang Sukabumi Village}

The pandemic's effects may be seen worldwide, especially in the Cinumpang village area in the Sukabumi district. According to an interview with Strawberry MSME actors, the situation in Sukabumi has improved after the outbreak. Considerable decreases in people's purchasing power were felt in various community economy sectors, both in data and daily. This deteriorating situation is palpable, and fast action is required, such as shifting purchases online during the peak of the pandemic breakout in mid-2020.

Although sales are not as high as before the pandemic, MSME actors in Cinumpang can still promote their products using Facebook Marketplace, Instagram, and other social media channels. You will need a Cinumpang-like box design and a wellpresented collection of product images to be enticing. Outside designers were also invited to help with the construction and design of appropriate packaging, including label stickers, for their strawberry souvenir products. Cinumpang's MSME actors perform online sales activities through Facebook and Instagram pages.

\subsection{Strategies to increase community profits and SMEs in Cinumang Village.}

To attract potential buyers, an aesthetic and appealing handling plan is required. In shape and label, buyers choose elegant, appealing packaging and deliver fascinating, up-to-date information and graphics [4]. The plan to raise awareness of Cinumpang MSME agribusiness products, 
specifically the Rizky Strawberry Cinumpang product, was divided into two parts:

\subsubsection{Packaging Strategy}

In the case of this strawberry, the packaging required is a souvenir product; therefore, the packaging can be chosen sensibly, both in terms of packing and the net weight of the souvenirs. According to statistics, $70 \%$ of visitors are adult women.

\subsubsection{Media Strategy}

\subsubsection{Media Partnership}
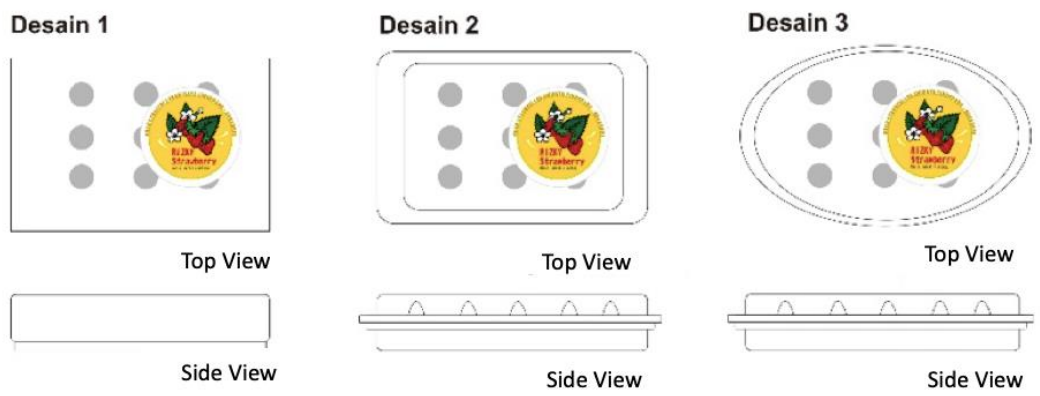

Figure 2. Strawberry packaging offered

The following are some of the designs available to Cinumpang MSMEs, as shown in the image above:

1) Design 1: a food-grade material constructed of laminated cardboard in a square shape. When put together in one secondary box (dozens), the advantages of this packaging style are maximal and neat space, while the disadvantage is that it seems stiff, leaving no holes between the primary boxes in the secondary package.

2) Design 2: the material is food-grade plastic with a bevel square. While this form's flaw is that it appears more generic, leaving a slight gap between the primary and secondary boxes. The advantages of this package design include full room, the minimal gap between the direct boxes, neatness when assembled in one secondary box (dozens), and a shape that is more flexible and acceptable to women.

3) Design 3: food-grade plastic with an ovalcylindrical form. While this design appears more general, it has many holes between the primary and secondary boxes, making it possible for shocks to occur during the distribution process. The benefits of this type of packaging are that it is more flexible, leaving much room between the top boxes
Media brings up the most basic form of packaging, namely packaging that comes into close contact with the content, strawberries. Because the fruit is perishable, a box with sufficient airflow and conditioning is required. Then pick a container that can hold the contents but is not impermeable. The container must also have a hollow element or lattice to keep the fruit wet and not stuffy on the inside. Food-grade standards and suitability for ingestion are essential elements to consider. This is because it is thought that when the fruit comes into contact with the contents, it will not harm the fruit while preserved, especially in a warm environment. and that the shape is more flexible and appealing to women.

\subsubsection{Secondary Media}

This secondary media packaging will assemble the primary media and allow shipping in larger quantities, such as dozens. In terms of visual use, it must also be consistent with the design's color palette - the colors employed in this package appeal to families, particularly women, who are the target market.

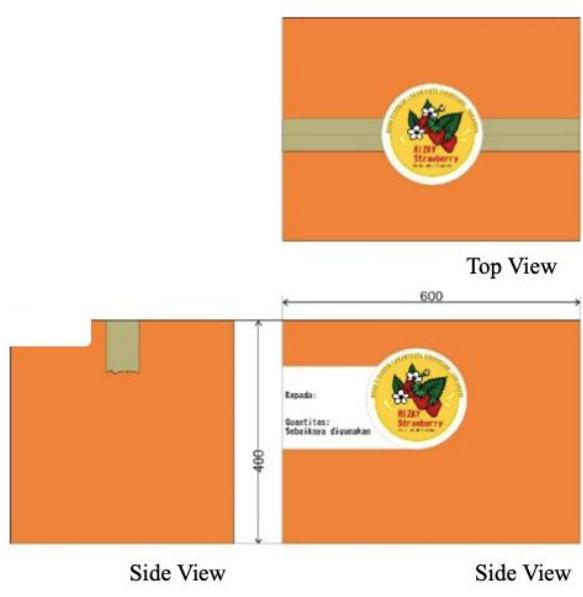

Figure 3. Secondary media design (cardboard packaging) 
The strawberry package logo necessitates a shape that can symbolize and appear happy and unique. The shape is inspired by the fruit and matches the styled plantation area, identical to the locals. This is meant to be suitably realistic, and the colors chosen are appropriate for the target market and appear to be happy. As a result of the formation, it is intended that it would also give the Cinumpang area a new and distinct look in addition to drawing fans.

The image above gives a pleasant impression because it does not employ the actual shape or photo but rather a joyful cartoon-style formation based on market needs, particularly ladies and mothers. The hues are highly appealing and eye-catching [5]. The most sought-after logos on product labels are in demand in the shape of adorable, beautiful, and dynamic images that awaken market tastes, produce insight, and instill a sense of trust in potential customers. In this scenario, it is crucial to emphasize that this sense of trust is vital to women as a market when they perceive and enjoy it [6].

\subsubsection{Design Concept}

Strawberries from this tourist attraction must have an appealing look and be able to be stored for some time before being delivered to their final destination, namely sales outlets. According to market demands, ordinary consumers desire a lowcost product with innovative and long-lasting packaging [7]. As a result of this necessity, an appealing form and packaging that is both reliable and resilient when supplied (trustworthy) will be required.

Because the market demands a practical container, it is decided to create one that is light and easy to produce because this production is in high demand and is sustainable; therefore, the packaging design might take the form of a roomy and sturdy box.

\subsubsection{Target Consumer}

According to experts in the field, the target buyers of strawberries from this tourist site are married women, who account for 73 percent of people who shop for strawberries at the location or online. Individuals and families consume souvenirs collectively and gifts for family and neighbors in the hamlet or city.

The sector, particularly the women's market, has a bright future. This is not a figment because women are associated with many products and services. This purposeful gender connection serves as complementary evidence of the facts on the ground and a new evaluation or a sign of future market supremacy, rather than just fitting and compulsion. [8]. The Women's market is also interested in the above explanation. When women see anything that looks cheery, appealing, current, amusing, healthy for the body, and fresh, they will enjoy it straight away and want to buy it [9].

Although it can be defined as a perception of data similarity shaped by various conditions and related contextual elements as determinants, past research has identified two primary bases. This is done in the hopes of making matches more successful and accessible. This compatibility can be seen in product attributes, brand image, and the consistency of a package media strategy. Park Milberg and Lawson propose that the evaluation process for existence be revisited frequently in the future, particularly for users and market researchers [2].

Table 1. Table of examples of brands labeled with gender

\begin{tabular}{|c|c|c|}
\hline Product Category & Masculine Brands & Feminine Brands \\
\hline Fragrance & Aramis, Hugo Boss & Estee Lauder, Elizabeth Arden \\
\hline Beauty Care Products & Clinique & Virginia Slims \\
\hline Tobacco & Marlboro & Chanel, Laura Ashley \\
\hline Fashion & Hugo Boss, Arrow & Victoria Secret, Triumph \\
\hline Undergarments/Negligee & Byford & Barbie \\
\hline Toys & Lego & \\
\hline
\end{tabular}


Even though it can be described as a perception of data similarity molded by many situations and related contextual elements as determinants, previous research has established two central bases. This is done to increase the success and accessibility of matches. This compatibility can be evident in product qualities, brand image, and package media strategy uniformity. Park Milberg and Lawson recommend revisiting the existing evaluation procedure regularly in the future, especially for consumers and market researchers [2]. Women are always positioned as facilitators and sweeteners for a goal in the public realm, with their physical appearance, symbols, and aspects, and vice versa. [9] As a result, the inclination to utilize softer, easier-toaccept colors and shapes will appear more suited to be incorporated to facilitate and streamline a capitalization flow. Smoother, fresher, and cheerier colors also correspond to the meaning and location of consumer products among women, though they can also be used for families. As a result, it has the potential to influence people's thinking and proclamation in the private sphere.

\subsubsection{Promotional Persuasion}

One of the areas of campaign classification is promotional techniques for executing their use and strategies. Promotion is a strategy for making it easier for business people to communicate the marketing of the products and services they offer, sell them and allow them to return and make transactions in the future, and become buyers who will always want these products and services. Product Oriented Campaigns are another term for this type of campaign. The main focus is on persuading potential customers to acquire various products and services to maximize profit margins.

\subsubsection{Colors and Shapes (Color Scheme)}

Packaging using an attractive color scheme invites the eyes of consumers who see are the target consumer of products that are of interest to producers [10]. The target can approach the realm of women because the main target of marketing and this market is promising now and in the future due to an increase of about $5.2 \%$ per year [8]. In public spaces, the intended color (mood) and the target must be at first glance like the primary target; it is possible that the colors displayed can enter the colors of children and families. This is because the colors displayed are fresh, happy, and give the impression of being bright, healthy, distinctive, family spirit, high potential, and assimilation. The packaging also gives a glimmer of hope so that the connoisseurs of UMKM souvenirs are very impressed with the freshness, regional spirit, and mild form that is quite rhythmic [9]. Packaging that is portable, practical, attractive, and easy to carry is the packaging that is in demand by consumers so that it is not a hassle when shopping and is light to carry also occupies a score of 4.22 from the respondent's field data that the author got [10].

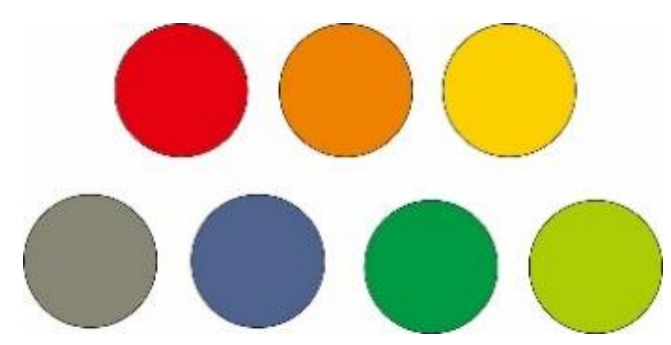

Figure 4. The color scheme used in the packaging

\subsubsection{Packaging Material}

Plastic or mica containers can be used for packaging, which is inexpensive to produce yet friendly to the contents of the packaging and the nature of the strawberry fruit (food grade). The package is excellent, and you can modify the content, which is a mix of fruits in a mica container. Due to collisions with other commodities, this packaging can also be flexible to follow the shape of the contents such as strawberries, papaya, grapes, and longan. The carrier aspect must be considered from the garden to the distribution process to the final destination store. The process was tested with a drop tester, assuming that it was sent by a cargo car and fell on the way. The results showed only a few bruises on the fruit (slight) and an index rating of 0.2 , indicating that the fruit was in relatively good condition [11].

The package can hold about 500 grams of fruit or 12 strawberries. Strawberries are wrapped fresh utilizing a packaging lock technique that involves using metal glue (stapler) or, if necessary, ziplock bags. Because the material is plastic, the stapler and ziplock locks are more appropriate and neat because they can prevent outside air from entering and maintain the temperature inside the package [12]. This stapler locking step was chosen due to cost considerations and tools that the Rizky Strawberry brand products can afford in the location where they are manufactured.

It takes roughly 15 seconds for each pack for workers to secure the packing with this stapler. Workers can perform this locking operation while also altering the position of the fruit to make it seem neat. This strategy allows potential female consumers to glimpse the contents of the fruit's 
freshness directly from the container, picking their curiosity.

\section{CONCLUSION}

The following are the findings drawn from some stages: 1) Packaging based on data gathered from the field, namely packaging must seem reasonable, and suited for women, suitable for strawberries, the color of the label chosen is an attractive color scheme., and excited. It is appropriate for the packaging to be attractive and easy to recall by the target market, based on the design determination.

\section{REFERENCES}

[1] P. Watts, Corporate social responsibility: meeting changing expectations. World Business Council for Sustainable Development, 1998.

[2] S. J. Brammer, C. Brooks, and S. Pavelin, "Corporate Social Performance and Stock Returns: UK Evidence from Disaggregate Measures," SSRN Electron. J., no. December 2019, 2011, doi: 10.2139/ssrn.739587.

[3] B. Arya and G. Zhang, "Institutional reforms and investor reactions to CSR announcements: Evidence from an emerging economy," J. Manag. Stud., vol. 46, no. 7, pp. 1089-1112, 2009, doi: 10.1111/j.14676486.2009.00836.x.

[4] I. Mahbubah and S. Subaida, "Corporate Social Responsibility: Building Corporate Image of Pt Bank Rakyat Indonesia, Tbk in Sumenep District," Int. Jt. Conf. ..., pp. 160163, 2020, [Online]. Available: https://journal.trunojoyo.ac.id/ijcst/article/v iew/8225.

[5] M. Jihadi, E. Vilantika, S. M. Hashemi, Z. Arifin, Y. Bachtiar, and F. Sholichah, "The Effect of Liquidity, Leverage, and Profitability on Firm Value: Empirical Evidence from Indonesia," J. Asian Financ. Econ. Bus., vol. 8, no. 3, pp. 423-431, 2021, doi: 10.13106/jafeb.2021.vol8.no3.0423.

[6] K. H. Titisari, K. Ratnawati, and N. K. Indrawati, "Mediation Role of Corporate Social Responsibility on Corporate Governance and Firm Value: Evidence from Indonesia Firms," IOSR J. Econ. Financ., vol. 9, no. 5, pp. 71-77, 2018, doi: 10.9790/5933-0905017177.
[7] A. Goss and G. S. Roberts, "The impact of corporate social responsibility on the cost of bank loans," J. Bank. Financ., vol. 35, no. 7, pp. 1794-1810, 2011, doi: 10.1016/j.jbankfin.2010.12.002.

[8] T. kasbi Ridho, "CSR In Indonesia: Company`s Perception And Implementation," EUrASEANs J. Glob. socio-economic Dyn., vol. 3, no. 4, pp. 6874, 2017.

[9] S. A. W. and S. B. Graves, "The Corporate Social Performance-Financial Performance Link," Strateg. Manag. J., vol. 18, no. 4, pp. 303-319, 1997, [Online]. Available: https://www.jstor.org/stable/3088143 .

[10] Y. K. F. Adrian Himawan Santoso, "The Association Between Corporate Social Responsibility And Corporate Financial Performance," Issues Soc. Environ. Account., vol. 8, no. 2, pp. 82-103, 2014, doi: dx.doi.org/10.22164/isea.v8i2.86.

[11] M. Masodah and M. Permanasari, "Bukti Empiris Pengaruh Corporate Social Responsibility Terhadap Tingkat Profitabilitas, Besaran Pajak Penghasilan, Dan Biaya Operasi Pada Perusahaan Yang Terdaftar Di Bursa Efek Indonesia," J. Ilm. Ekon. Bisnis, 2012, doi: 10.35760/eb. 